\title{
A foreign body in the rectum
}

\author{
Gabriel Sunil Rodrigues · Dileep Namvar Lobo
}

Received: 20 February 2009 / Accepted: 26 February 2009

(C) Association of Surgeons of India 2009

A woman presented to the emergency department, having inserted a vibrator without batteries into her rectum after her 47 th birthday celebrations. There were no other symptoms and on examination the abdomen, anus and rectum were normal. A plain X-ray of the abdomen showed the foreign body (Fig. 1). The object was not visualised with a rigid sigmoidoscope inserted to $20 \mathrm{~cm}$. She was planned for a laparotomy and was prescribed $60 \mathrm{ml}$ lactulose. Surprisingly, she passed the foreign body (FB) spontaneously 6 hours later.

Rectal FB should be suspected when faced with either pelvic or perianal low abdominal pain and/or a rectal haemorrhage, in the context of a dubious story in cases without a medical history of recent instrumental diagnostic or therapeutical exploration. The clinical presentation is varied, depending on the presence or absence of complications (being anal perforation, peritonitis and intra-abdominal abscesses) [1]. Diagnosis is confirmed with radiological tests (plain-film abdominal radiography is the recommended first-line approach, as the objects are usually radio-opaque) and with a rectal examination. Many of these objects can be extracted transanally in the emergency department;

G. S. Rodrigues · D. N. Lobo

Division of Gastrointestinal Surgery,

Wolfson Digestive Diseases Centre,

Nottingham University Hospitals,

Queen's Medical Centre,

Nottingham, UK

G. Rodrigues $(\bowtie)$

E-mail: gabyrodricks@gmail.com

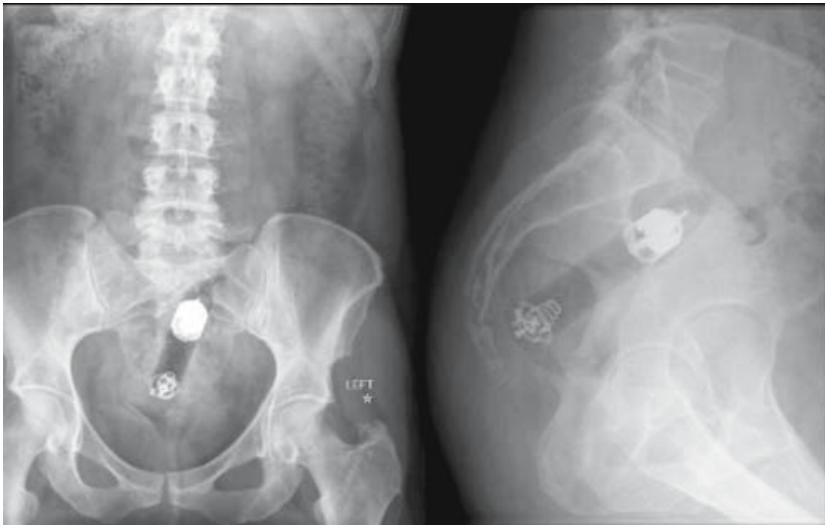

Fig. 1 Plain X-ray showing rectal foreign body

however, if this is not possible, surgical extraction should be considered. Open surgery under general anaesthesia must be reserved only for those patients with very large objects or those suffer from peritonitis due to rectal perforation or pelvic sepsis. Although the majority of patients with rectal FB require an examination under anaesthesia or even, on occasion, a laparotomy for removal, a few FB may pass spontaneously after the administration of enemas or laxatives [2]. After FB extraction, all patients must remain in observation to exclude possible rectal perforation.

\section{References}

1. Clarke DL, Buccimazza I, Anderson FA, et al. (2005) Colorectal foreign bodies. Colorectal Dis 7:98-103

2. Rodríguez-Hermosa JI, Codina-Cazador A, Ruiz B, et al. (2007) Management of foreign bodies in the rectum. Colorectal Dis 9:543-548 